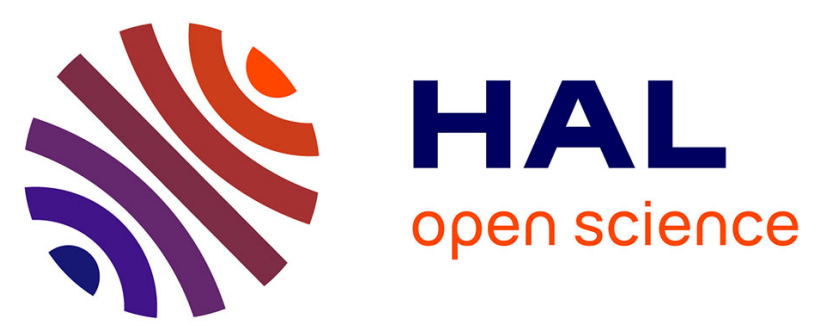

\title{
Influence of the copper deficiency and anionic composition on band-energy diagram of bulk kesterite CZTSSe
}

\author{
P. Bais, M.T. Caldes, C. Guillot-Deudon, Adele Renaud, M. Boujtita, S. \\ Jobic, Alain Lafond
}

\section{To cite this version:}

P. Bais, M.T. Caldes, C. Guillot-Deudon, Adele Renaud, M. Boujtita, et al.. Influence of the copper deficiency and anionic composition on band-energy diagram of bulk kesterite CZTSSe. Materials Research Bulletin, 2021, 139, pp.111285. 10.1016/j.materresbull.2021.111285 . hal-03196101

\section{HAL Id: hal-03196101 \\ https://hal.science/hal-03196101}

Submitted on 21 Apr 2021

HAL is a multi-disciplinary open access archive for the deposit and dissemination of scientific research documents, whether they are published or not. The documents may come from teaching and research institutions in France or abroad, or from public or private research centers.
L'archive ouverte pluridisciplinaire HAL, est destinée au dépôt et à la diffusion de documents scientifiques de niveau recherche, publiés ou non, émanant des établissements d'enseignement et de recherche français ou étrangers, des laboratoires publics ou privés. 
Influence of the copper deficiency and anionic composition on band-energy diagram of bulk kesterite CZTSSe

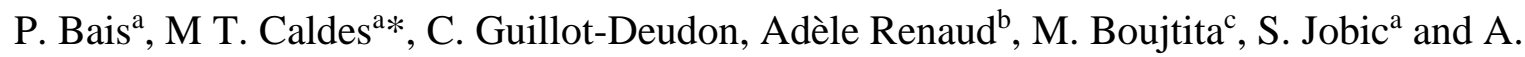
Lafond $^{\text {a }}$

${ }^{a}$ Université de Nantes, CNRS, Institut des Matériaux Jean Rouxel, IMN, F-44000 Nantes, France

${ }^{b}$ Univ Rennes, CNRS, ISCR - UMR 6226, 35000 Rennes, France

${ }^{c}$ Université de Nantes, CNRS, CEISAM UMR 6230, F-44000 Nantes, France

*E-mail: maite.caldes@cnrs-imn.fr

Graphical abstract

\section{Kesterite CZTSSe}
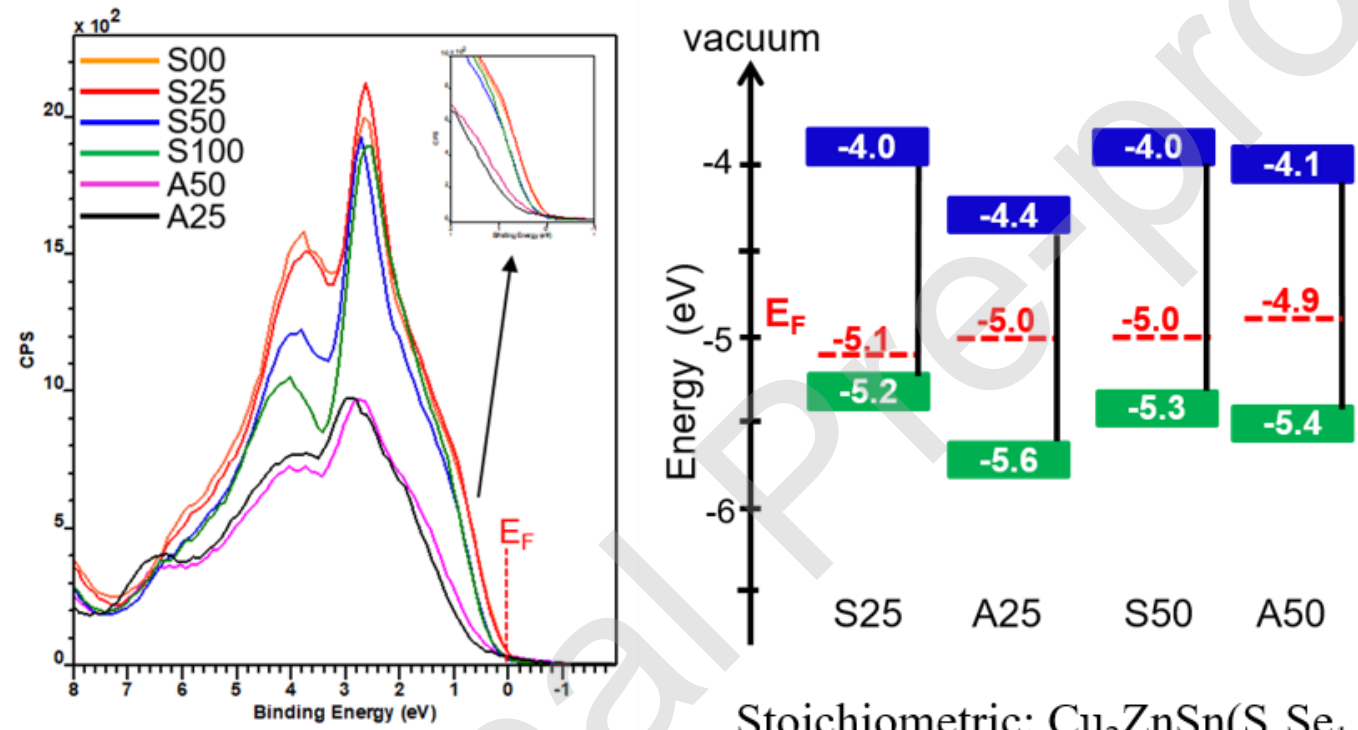

Stoichiometric: $\mathrm{Cu}_{2} \mathrm{ZnSn}\left(\mathrm{S}_{\mathrm{x}} \mathrm{Se}_{1-\mathrm{x}}\right)_{4}$

Cu-poor: $\mathrm{Cu}_{1.7} \mathrm{Zn}_{1.15} \mathrm{Sn}\left(\mathrm{S}_{\mathrm{x}} \mathrm{Se}_{1-\mathrm{x}}\right)_{4}$

Highlights

- The influence of the Cu-deficiency on band-energy diagram of CZTSSe was investigated

- Cu-deficiency enhances optical absorption without modification of the optical gap

- $\mathrm{Cu}$ off-stoichiometry influences notably the positioning of $\mathrm{E}_{\mathrm{F}}$ into the band gap

- The VBM shifts towards a deeper energy level 
- $\mathrm{Cu}$ non-stoichiometry appears as a key point to design suitable CZTSSe PV absorbers

\begin{abstract}
The influence of the chemical composition on band edges and Fermi level of the $\mathrm{Cu}_{2} \mathrm{ZnSn}\left(\mathrm{S}_{\mathrm{x}} \mathrm{Se}_{1-\mathrm{x}}\right)_{4}$ stoichiometric compounds was investigated. The $\mathrm{Cu}$-poor compounds, $\mathrm{Cu}_{1.70} \mathrm{Zn}_{1.15} \mathrm{SnSSe}_{3}$ and $\mathrm{Cu}_{1.70} \mathrm{Zn}_{1.15} \mathrm{SnS}_{2} \mathrm{Se}_{2}$, were also studied according to the same approach. As already reported, the absorption threshold increases linearly from $\mathbf{1 . 0 5}$ to $1.48 \mathrm{eV}$ with increasing sulfur content. Simultaneously, the conduction band moves from 4.4 to $-3.8 \mathrm{eV}$ respectively, while the position of the uppermost level of the valence bands and the Fermi levels are almost not influenced by the S/Se ratio. In contrast, for $\mathrm{Cu}$-poor compounds, a significant change in the chemical surface composition is witnessed compared to that of the bulk. Moreover, the absorption capability is enhanced without modification of the optical gap. The Cu off-stoichiometry influences also notably the positioning of Fermi level into the band gap. These features could be at the origin for the singular performances of the $\mathrm{Cu}$ poor CZTSSe-based solar cell.
\end{abstract}

Keywords: $\mathrm{Cu}_{2} \mathrm{ZnSn}(\mathrm{S}, \mathrm{Se})_{4}$, photovoltaics, $\mathrm{Cu}$-poor, flat band potentials, XPS

\title{
1. Introduction
}

Although copper zinc tin chalcogenides (CZTSSe) have been extensively studied as photovoltaic absorbers, the related thin film solar cells remain with unsatisfactory performances $(\eta<12 \%)$. Short minority carrier lifetime and low open circuit voltage $\left(\mathrm{V}_{\mathrm{oc}}\right)$ have been identified as the key issues for CZTSSe materials [1-2]. Formally, cationic and anionic disorders, i.e. random distributions of $\mathrm{Cu}$ and $\mathrm{Zn}$ as well as $\mathrm{S}$ and $\mathrm{Se}$ at specific 
crystallographic sites of the kesterite-type structure [3-4], could impact these characteristics. However, Cu-poor CZTSSe materials appear to have better performances than their stoichiometric derivatives [5]. In that context, using advanced crystallographic techniques, a classification of point defect clusters occurring in $\mathrm{Cu}$-poor $\mathrm{Cu}_{2-2 \mathrm{a}} \mathrm{Zn}_{1+\mathrm{a}} \mathrm{Sn}\left(\mathrm{S}_{\mathrm{x}} \mathrm{Se}_{1-\mathrm{x}}\right)_{4}$ series was proposed (e.g. $2 \mathrm{Cu}_{\mathrm{Cu}} \rightarrow \mathrm{Zn}_{\mathrm{Cu}}+\mathrm{V}_{\mathrm{Cu}}$ corresponds to the A-Type defects, $2 \mathrm{Cu}_{\mathrm{Cu}}+\mathrm{Sn}_{\mathrm{Sn}} \rightarrow 2 \mathrm{Zn}_{\mathrm{Cu}}$ $+\mathrm{Zn}_{\mathrm{Sn}}$ to the $\mathrm{B}$ ones) [6-8]. It was shown that A-type defect could limits cationic disorder which could explain the best optoelectronic properties of $\mathrm{Cu}$-poor CZTSSe compounds [4].

On the other hand, it is well known that the efficiency of a solar cell is strongly correlated to the band alignment between the absorber and the buffer materials, and specifically to the conduction band offsets (CBO) [9]. For CZTSSe compounds, the dependence of the bandgap and the band edge position versus the anionic composition ( $\mathrm{S} / \mathrm{Se})$ has been studied theoretically (first-principles calculations) and experimentally (both electrochemical and spectroscopic methods). In the specific case of a CZTSSe/CdS heterojunction, the offset has been directly determined by several spectroscopic techniques [10]. However, its magnitude and its type (i.e. "spike-like" or "cliff-like") are still subject to debate. One possible reason to account for this still-existing controversy is chemical interdiffusion at the interface region that would strongly impact $\mathrm{CBO}[9]$.

At that time, most studies reported in the literature on CZTS concern solely thin films or nanocrystals where an accurate determination of the chemical composition remains naturally difficult. Unfortunately, stoichiometry control is a key parameter since CZTSSe single-phased compounds exist only in a very narrow region of the pseudo-ternary $\mathrm{Cu}_{2}(\mathrm{~S}, \mathrm{Se})-\mathrm{Zn}(\mathrm{S}, \mathrm{Se})$ $\mathrm{Sn}(\mathrm{S}, \mathrm{Se})_{2}$ phase diagram $[3,11-14]$. Thus, off-stoichiometric CZTS and secondary phases are easily formed during the growth and post-growth processes, impacting possibly CBO and consequently solar cell performances [5, 15-16]. To better understand the influence of the anionic composition of CZTSSe on band edges (with possibility to fine-tune the CBO in 
ultimate device approach), we prepared $\mathbf{C u}_{2} Z_{\mathbf{Z}} \mathbf{n}_{0.5} \mathbf{S n}_{\mathbf{0 . 5}}\left(\mathbf{S}_{\mathbf{x}} \mathbf{S e}_{1-\mathrm{x}}\right)_{4}(0 \leq \mathrm{x} \leq 1)$ compounds as bulk materials. In parallel, to get insight on the property change induced by a copper substoichiometry, two Cu-poor compounds, namely $\mathrm{Cu}_{1.70} \mathrm{Zn}_{1.15} \mathrm{SnSSe}_{3}$ and $\mathrm{Cu}_{1.70} \mathrm{Zn}_{1.15} \mathrm{SnS}_{2} \mathrm{Se}_{2}$, were prepared and their characteristics compared to those of related stoichiometric compounds. The energy diagrams of all compounds on an absolute scale were determined combining diffuse reflectance, electrochemical impedance spectroscopy (EIS) and X-ray photoelectron spectroscopy (XPS) measurements.

\section{Experimental}

The $\mathrm{Cu}_{2} \mathrm{ZnSn}\left(\mathrm{S}_{\mathrm{x}} \mathrm{Se}_{1-\mathrm{x}}\right)_{4}$ stoichiometric compounds $(0 \leq \mathrm{x} \leq 1)$ (i.e. $\mathrm{Cu}_{2} \mathrm{ZnSnSe}_{4}(\mathrm{~S} 00)$, $\mathrm{Cu}_{2} \mathrm{ZnSnS}_{1} \mathrm{Se}_{3}(\mathrm{~S} 25), \mathrm{Cu}_{2} \mathrm{ZnSnS}_{2} \mathrm{Se}_{2}(\mathrm{~S} 50)$ and $\left.\mathrm{Cu}_{2} \mathrm{ZnSnS}_{4}(\mathrm{~S} 100)\right)$ and the $\mathrm{Cu}$-poor compounds $\mathrm{Cu}_{1.70} \mathrm{Zn}_{1.15} \mathrm{SnS}_{1} \mathrm{Se}_{3}$ (A25) and $\mathrm{Cu}_{1.70} \mathrm{Zn}_{1.15} \mathrm{SnS}_{2} \mathrm{Se}_{2}$ (A50) were elaborated from the constitutive chemical elements (elemental $\mathrm{Cu}, \mathrm{Zn}, \mathrm{Sn}, \mathrm{S}$ and $\mathrm{Se}$ ) via a ceramic route as previously reported [6]. The purity of the samples was checked by powder X-ray diffraction and by scanning electron microscopy (SEM) backscattered imaging. The exact chemical composition was determined by Energy-dispersive X-ray analyses (EDX). The analyses were performed on polished sections of the samples embedded in epoxy using calibrated standards. Table 1 sums up the target and measured compositions as well as the labelling used hereafter. 
Table 1: Labelling and measured chemical compositions of $\mathrm{Cu}_{2} \mathrm{ZnSn}\left(\mathrm{S}_{\mathrm{x}} \mathrm{Se}_{1-\mathrm{x}}\right)_{4}$ and $\mathrm{Cu}-$ poor samples

\begin{tabular}{llll}
\hline sample & targeted composition & $\begin{array}{l}\text { EDX } \\
\text { Composition* }\end{array}$ & $\mathbf{x}($ EDX) \\
\hline $\mathbf{S 0 0}$ & $\mathrm{Cu}_{2} \mathrm{ZnSnSe}_{4}$ & $\mathrm{Cu}_{1.98(1)} \mathrm{Zn}_{1.02(2)} \mathrm{Sn}_{0.996(6)} \mathrm{Se}_{4.00(2)}$ & 0 \\
$\mathbf{S 2 5}$ & $\mathrm{Cu}_{2} \mathrm{ZnSnS}_{1} \mathrm{Se}_{3}$ & $\mathrm{Cu}_{1.99(2)} \mathrm{Zn}_{0.99(1)} \mathrm{Sn}_{1.019(7)} \mathrm{S}_{1.05(1)} \mathrm{Se}_{2.947(7)}$ & $0.263(2)$ \\
$\mathbf{A 2 5}$ & $\mathrm{Cu}_{1.70} \mathrm{Zn}_{1.15} \mathrm{SnS}_{1} \mathrm{Se}_{3}$ & $\mathrm{Cu}_{1.81(2)} \mathrm{Zn}_{1.18(4)} \mathrm{Sn}_{1.006(9)} \mathrm{S}_{1.08(1)} \mathrm{Se}_{2.923(9)}$ & $0.268(3)$ \\
$\mathbf{S 5 0}$ & $\mathrm{Cu}_{2} \mathrm{ZnSnS}_{2} \mathrm{Se}_{2}$ & $\mathrm{Cu}_{1.98(2)} \mathrm{Zn}_{1.01(2)} \mathrm{Sn}_{1.005(7)} \mathrm{S}_{2.09(2)} \mathrm{Se}_{1.910(7)}$ & $0.523(5)$ \\
$\mathbf{A 5 0}$ & $\mathrm{Cu}_{1.70} \mathrm{Zn}_{1.15} \mathrm{SnS}_{2} \mathrm{Se}_{2}$ & $\mathrm{Cu}_{1.83(4)} \mathrm{Zn}_{1.15(2)} \mathrm{Sn}_{1.01(1)} \mathrm{S}_{2.11(3)} \mathrm{Se}_{1.99(1)}$ & $0.528(2)$ \\
$\mathbf{S 1 0 0}$ & $\mathrm{Cu}_{2} \mathrm{ZnSnS}_{4}$ & $\mathrm{Cu}_{1.99(2)} \mathrm{Zn}_{0.99(2)} \mathrm{Sn}_{1.02(1)} \mathrm{S}_{4.000(9)}$ & 1 \\
\hline
\end{tabular}

*Estimated standard deviations are given in parentheses

The UV-visible-NIR diffuse reflectance spectra of finely ground samples were recorded with a UV-vis/NIR spectrometer (Perkin Elmer Lambda 1050) equipped with an integration sphere and controlled using the UV Winlab 6 program. The reflectance measurements were made in the $1653-496 \mathrm{~nm}$ range (i.e. from 0.75 to $2.5 \mathrm{eV}$ ) with a $2 \mathrm{~nm}$ step. Barium carbonate was used as white standard. The absorption (K/S) data were then calculated from the raw reflectance data using the $\mathrm{K} / \mathrm{S}=(1-\mathrm{R})^{2} /(2 \mathrm{R})$ Kubelka-Munk formula. Spectra have been normalized for easy comparison.

X-ray photoemission measurements were performed on a Kratos AXIS ultra-spectrometer using a monochromatic Al Ka X-ray source (1486.6 eV). The X-ray source ran at $150 \mathrm{~W}$ and the analyzed area was $700 \times 300 \mu \mathrm{m}^{2}$. The spectrometer was calibrated using $\mathrm{Au} 4 \mathrm{f}_{7 / 2}$ at 83.97 $\mathrm{eV}$ and $\mathrm{Cu} 2 \mathrm{p}_{3 / 2}$ peaks at $923.63 \mathrm{eV}$ measured from sputter-cleaned $\mathrm{Au}$ and $\mathrm{Cu}$ films. The $\mathrm{Ag}$ $3 \mathrm{~d}_{5 / 2} \mathrm{FWHM}$ is $0.47 \mathrm{eV}$ at $20 \mathrm{eV}$ pass energy giving an instrumental resolution of $0.1 \mathrm{eV}$. The sound samples were ground and pressed into $6 \mathrm{~mm}$ diameter pellets and annealed at $350^{\circ} \mathrm{C}$ in sealed silica tubes in order to avoid grain surface oxidation. The tubes were opened in a glove box and mounted on double-sided carbon tape on an aluminium plate and transferred to the XPS spectrometer using a bag under argon to limit surface oxidation. The wide scans were 
systematically recorded with a pass energy of $160 \mathrm{eV}$. For all compounds, high resolution spectra of C1s, O1s, Cu2p, Zn2p, Sn3d, S2p/Se2p core levels and valence bands (VB) were acquired at $20 \mathrm{eV}$ pass energy. The intensities of the $\mathrm{C} 1 \mathrm{~s}$ and $\mathrm{O} 1 \mathrm{~s}$ peaks were very low and similar for all compounds, in good agreement with a little contamination of the surfaces. In addition, the C1s peak was used as energy reference $(284.8 \mathrm{eV})$. Spectra analysis was done using CASA XPS program [17]. All the spectra were fitted using Voigt functions and a linear background. A constraint on the area ratio according to their multiplicity (i.e. S2p1/2 and S2p3/2) was systematically applied.

Electrochemical impedance spectroscopy (EIS) measurements were performed in a threeelectrode electrochemical cell using platinum as counter electrode, a saturated calomel electrode (SCE) as reference electrode and CZTSSe pellets as working electrode. $\mathrm{A} \mathrm{LiClO}_{4}(1$ M) aqueous solution (5.4 - 7.7 $\mathrm{pH}$ range) was used as electrolyte. Pellets were pressed under 0.6 MPa and sintered at $600^{\circ} \mathrm{C}$ for $48 \mathrm{~h}$ into a sealed silica tube. The more friable $\mathrm{Cu}$-poor compounds were consolidated by spark plasma sintering (FAST/SPS, FCT System GmbH, model HP D10-SD) as reported in [18]. The sample powder was pressed at $410^{\circ} \mathrm{C}$ for 5 min under uniaxial pressure of $60 \mathrm{MPa}$ under an argon atmosphere in a high-density graphite die. Each sintered pellet was connected to a cooper wire using a silver conductive paste, then mounted in a chemical epoxy resin and polished to give a smooth electrode surface. For $\mathrm{Cu}$ poor samples, a $\mathrm{KCl}(0.5 \mathrm{M})$ aqueous solution $(6.3-7.2 \mathrm{pH}$ range $)$ was used as electrolyte. Impedance spectra were obtained under AC voltage $(10 \mathrm{mV}$ amplitude and $100 \mathrm{~Hz}-100 \mathrm{kHz}$ frequency range) in a potential ranging from -0.8 to $0 \mathrm{~V} v s$. SCE. In order to determine the flat-band potential $\left(\mathrm{V}_{\mathrm{fb}}\right)$, EIS spectra were analyzed using the Mott-Schottky method [19] at high frequencies $(1-10 \mathrm{kHz})$. 


\section{Results and Discussion}

3.1 Optical band gaps.

Figure 1a shows the Kubelka-Munk transformed reflectance spectra of the four stoichiometric CZTSSe compounds. Their chemical compositions are indicated in Table 1 (see Experimental section). The estimated absorption thresholds, taken at the inflexion point, continuously increase from 1.05 to $1.16,1.28$ and $1.48 \mathrm{eV}$ for corresponding targeted $\mathrm{x}$ values (i.e. $0,0.25,0.5$ and 1$)$, according an empirical $y(e V)=0.43 x^{\prime}+1.05$ formula where $x^{\prime}$ is the exact $\mathrm{S} /(\mathrm{S}+\mathrm{Se})$ ratio determined by EDX. The linear variation of the gap is directly related to that of the unit cell parameters which follow a Vegard' law. Let us notice that these measured gap values are in a good agreement with those reported in the literature [20-22].
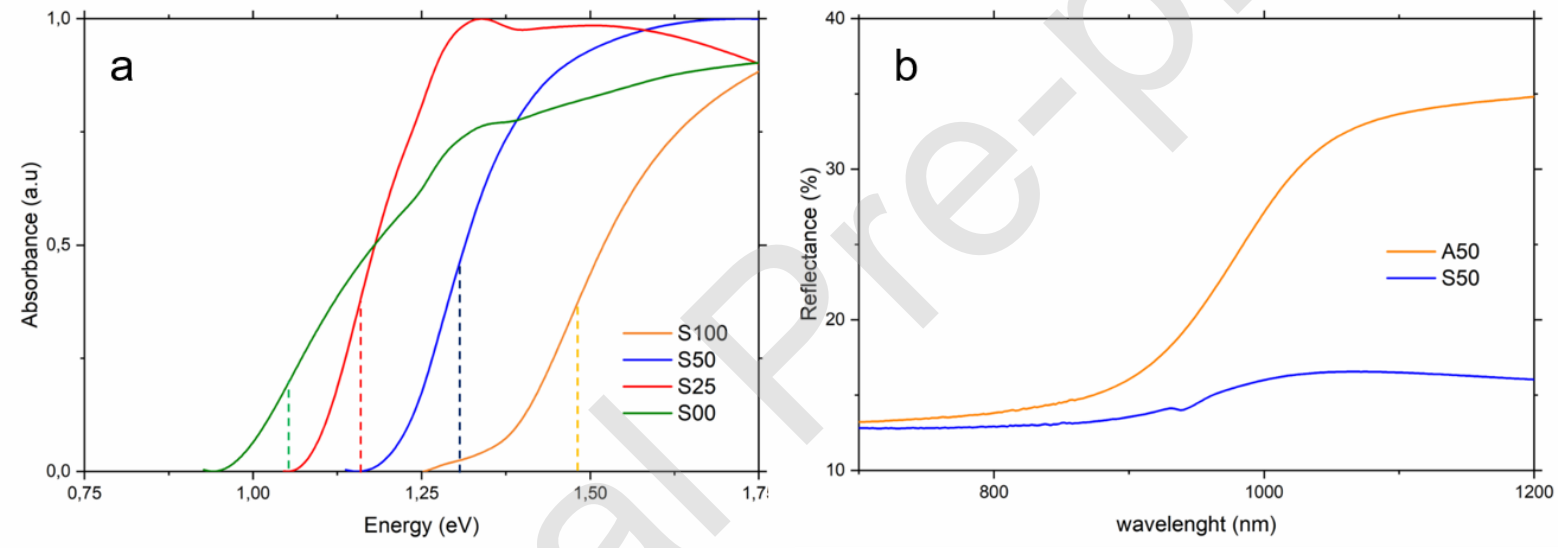

Figure 1: (a) Kubelka-Munk transformed reflectance spectra of stoichiometric CZTSSe compounds. Dotted lines point out the inflection points considered to calculate the absorption thresholds, (b) reflectance spectra of S50 and A50 compounds

Let us now compare the reflectance spectra (see Figure 1b) of stoichiometric S50 compound $\left(\mathrm{Cu}_{1.98(2)} \mathrm{Zn}_{1.01(2)} \mathrm{Sn}_{1.005(7)} \mathrm{S}_{2.09(2)} \mathrm{Se}_{1.910(7)}\right)$ and its $\mathrm{A} 50 \mathrm{Cu}-$ poor variant $\left(\mathrm{Cu}_{1.83(4)} \mathrm{Zn}_{1.15(2)} \mathrm{Sn}_{1.01(1)} \mathrm{S}_{2.11(3)} \mathrm{Se}_{1.99(1)}\right)$. It is worth noting that the optical gaps remain unchanged for both materials but the absorption onset is much steeper for A50 than S50. To 
check whether this is related to a scattering effect depending on particle size, both powdered samples underwent several grindings and no modification of the reflectance spectra was observed. Thus, this strong difference in the reflecting behavior at low energy is associated to the change in chemical composition of the bulk materials. and more precisely to the $\mathrm{Cu}$ offstoichiometry known to limit naturally the $\mathrm{Cu} / \mathrm{Zn}$ disorder in kesterite [3].

\subsection{Band-Edge energies and Flat band potentials}

In order to determine the position of the valence band maximum (VBM), XPS measurements were undertaken. For all collected spectra, the signal-to-noise ratio is high and makes stronger our forthcoming arguments. The valence band spectra of the stoichiometric and $\mathrm{Cu}$-poor CZTSSe compounds are displayed in Figure 2a.

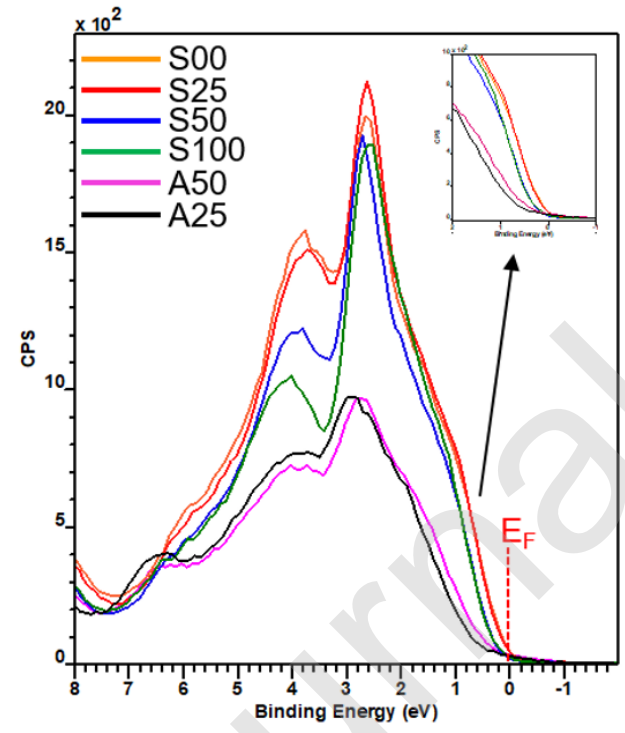

a
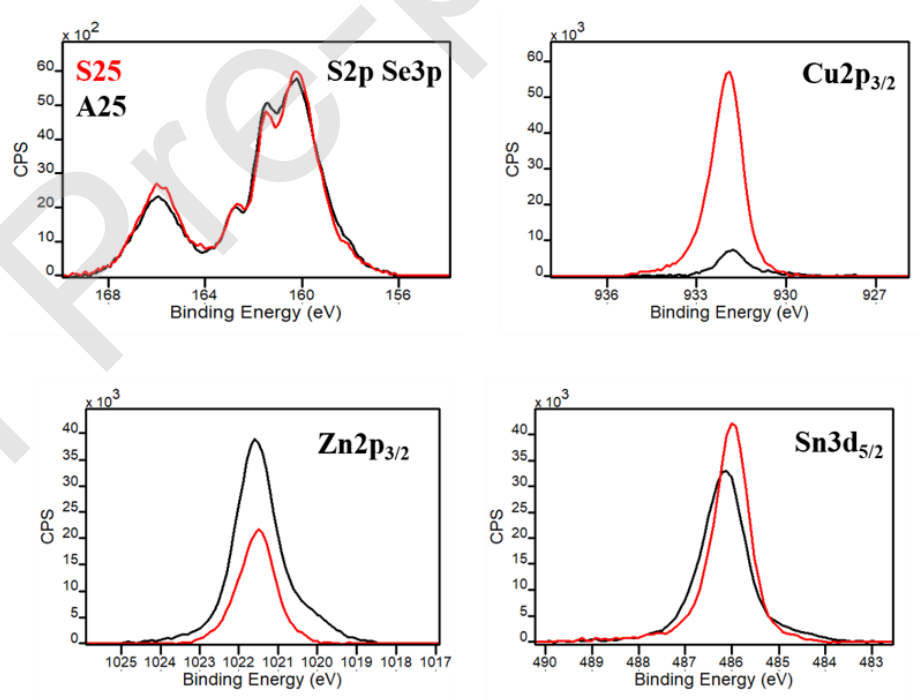

b

Figure 2: (a) XPS spectra of stoichiometric and Cu-poor CZTSSe materials, (b) XPS spectra at $\mathrm{S} 2 \mathrm{p}, \mathrm{Se} 3 \mathrm{p}, \mathrm{Cu} 2 \mathrm{p}_{3 / 2}, \mathrm{Zn} 2 \mathrm{p}_{3 / 2}$ and $\mathrm{Sn} 3 \mathrm{~d}_{5 / 2}$ threshold of $\mathrm{S} 25$ and A25 samples.

Namely, going from $\mathrm{Cu}_{2} \mathrm{ZnSnSe}_{4}$ to $\mathrm{Cu}_{2} \mathrm{ZnSnS}_{4}$, the binding energy associated to the $\mathrm{VBM}$ varies from $0.1 \mathrm{eV}$ to $0.3 \mathrm{eV}$ with respect to the Fermi level set at zero eV. For A25 and A50, 
the valence band is clearly shifted towards higher binding energies (VBM at $0.6 \mathrm{eV}$ and 0.5 $\mathrm{eV}$, respectively) supporting a deeper valence band. It is also striking that a much higher density of states at the top of the VB (built upon $\mathrm{Cu}-3 \mathrm{~d}$ orbitals) [23] is evidenced for all stoichiometric compounds compared to non-stoichiometric ones, in agreement with a higher concentration of $\mathrm{Cu}$ in the targeted composition. This last observation is fully supported by comparing the analyses of surface compositions of S25 and S50 samples to those of A25 and A50 ones (see Table 2).

Table 2. Chemical composition of the surfaces of S25, A25, S50 and A50 samples determined by XPS measurements. Expected values from the EDX analyses are given in parentheses in italics.

\begin{tabular}{lllll}
\hline At. \% ratios & $\mathbf{C u} / \mathbf{Z n + S n}$ & $\mathbf{Z n} / \mathbf{Z n + S n}$ & $\mathbf{S n} / \mathbf{Z n + S n}$ & $\mathbf{S} / \mathbf{S e}$ \\
\hline S25 & $1.3(1.0)$ & $0.4(0.5)$ & $0.6(0.5)$ & $0.3(0.4)$ \\
A25 & $0.1(0.3)$ & $0.6(0.4)$ & $0.4(0.4)$ & $0.2(0.4)$ \\
S50 & $1.1(1.0)$ & $0.4(0.5)$ & $0.6(0.5)$ & $0.6(1.1)$ \\
A50 & $0.2(0.9)$ & $0.6(0.5)$ & $0.4(0.5)$ & $0.5(1.1)$ \\
\hline
\end{tabular}

To do this, the cationic core level spectra (i.e. Cu2p, Zn2p, Sn3d) were normalized with respect to those of $\mathrm{S} 2 \mathrm{p} / \mathrm{Se} 3 \mathrm{p}$ and superimposed for each cation (see Figure 2). Let us consider A25 and S25 samples. Results indicate an under-representation of copper coupled to an overrepresentation of zinc at the surfaces of A25 compared to S25. Although both compounds exhibit the S/Se ratios quite similar to those expected, their cation surface compositions are clearly distinguishable. Indeed, the already existing $\mathrm{Cu}$ deficit in the A25 bulk material is significantly reinforced at the surface. The $\mathrm{Cu} /(\mathrm{Zn}+\mathrm{Sn})$ ratio shifts from 1.3 to 0.1 from $\mathrm{S} 25$ to A25. Simultaneously, the $\mathrm{Zn} /(\mathrm{Zn}+\mathrm{Sn})$ ratio increases from 0.4 to 0.6 while the $\mathrm{Sn} /(\mathrm{Zn}+\mathrm{Sn})$ follows the exact opposite trend (from 0.6 to 0.4 ). This analysis is also valid for the A50 and 
S50 compounds excepting for the S/Se ratio which is lower than expected, indicating an enrichment of the surface in Se.

The strong $\mathrm{Cu}$-depletion observed in both $\mathrm{Cu}$-poor samples at their surface, might be due to the occurrence of A-type substitution defects (i.e. $2 \mathrm{Cu}_{\mathrm{Cu}} \rightarrow \mathrm{Zn}_{\mathrm{Cu}}+\mathrm{V}_{\mathrm{Cu}}$ ), already observed in these bulk materials. Furthermore, B-type substitution defects (i.e. $2 \mathrm{Cu}_{\mathrm{Cu}}+\mathrm{Sn}_{\mathrm{Sn}} \rightarrow 2 \mathrm{Zn}_{\mathrm{Cu}}$ $\left.+\mathrm{Zn}_{\mathrm{Sn}}\right)$ could explain the opposite evolution of the $\mathrm{Zn} /(\mathrm{Zn}+\mathrm{Sn})$ and $\mathrm{Sn} /(\mathrm{Zn}+\mathrm{Sn})$ ratios. This change in composition from the core to the shell should also drastically modify the optoelectronic characteristics of surfaces compared to bulk, and surely impact significantly the overall photovoltaic performances of a CZTSSe-based solar cell.

In order to propose energy-level diagrams of all samples on an absolute energy scale (AVS), flat-band potentials $\left(\mathrm{V}_{\mathrm{fb}}\right)$ were determined via EIS measurements to position their Fermi level.

The method is founded on the Mott-Schottky relationship: $1 / \mathrm{C}_{\mathrm{sc}}{ }^{2}=2 / \varepsilon \varepsilon_{0} \mathrm{e} \mathrm{A}^{2} \mathrm{~N}\left(\mathrm{~V}-\mathrm{V}_{\mathrm{fb}}-\right.$ $\mathrm{kT} / \mathrm{e}$ ) where $\mathrm{C}_{\mathrm{SC}}$ is the capacitance of the space charge region in the semiconductor, At the interfacial surface area between the semiconductor electrode and the electrolyte, $\varepsilon_{0}$ the vacuum permittivity, $\varepsilon$ the relative permittivity of the semiconductor, $\mathrm{N}$ majority charge carrier density, $\mathrm{k}$ the Boltzmann constant, $\mathrm{T}$ the temperature and e the electron charge. It involves thus determining the capacitance at the semiconductor/electrolyte interface (C) as a function of potential (V). In fact, at the semiconductor-electrolyte interface two capacitances in series could be considered, that of the space charge region $\left(\mathrm{C}_{\mathrm{SC}}\right)$ and that of the Helmholtz layer $\left(\mathrm{C}_{\mathrm{H}}\right)$. Thus, the total capacitance is the addition of their reciprocals $\left(\mathrm{C}^{-2}=\mathrm{CSC}^{-2}+\mathrm{CH}^{-2}\right)$. For calculations, $\mathrm{C}^{-2}$ is assumed to be equal to $\mathrm{CSC}^{-2}$ since the capacity of the Helmholtz layer is notably higher than the space charge region capacity. Mott-Schottky plots $\left(1 / \mathrm{C}_{\mathrm{sc}}{ }^{2} v s\right.$. V) for all stoichiometric CZTSSe compounds are shown in Figure 3a. 

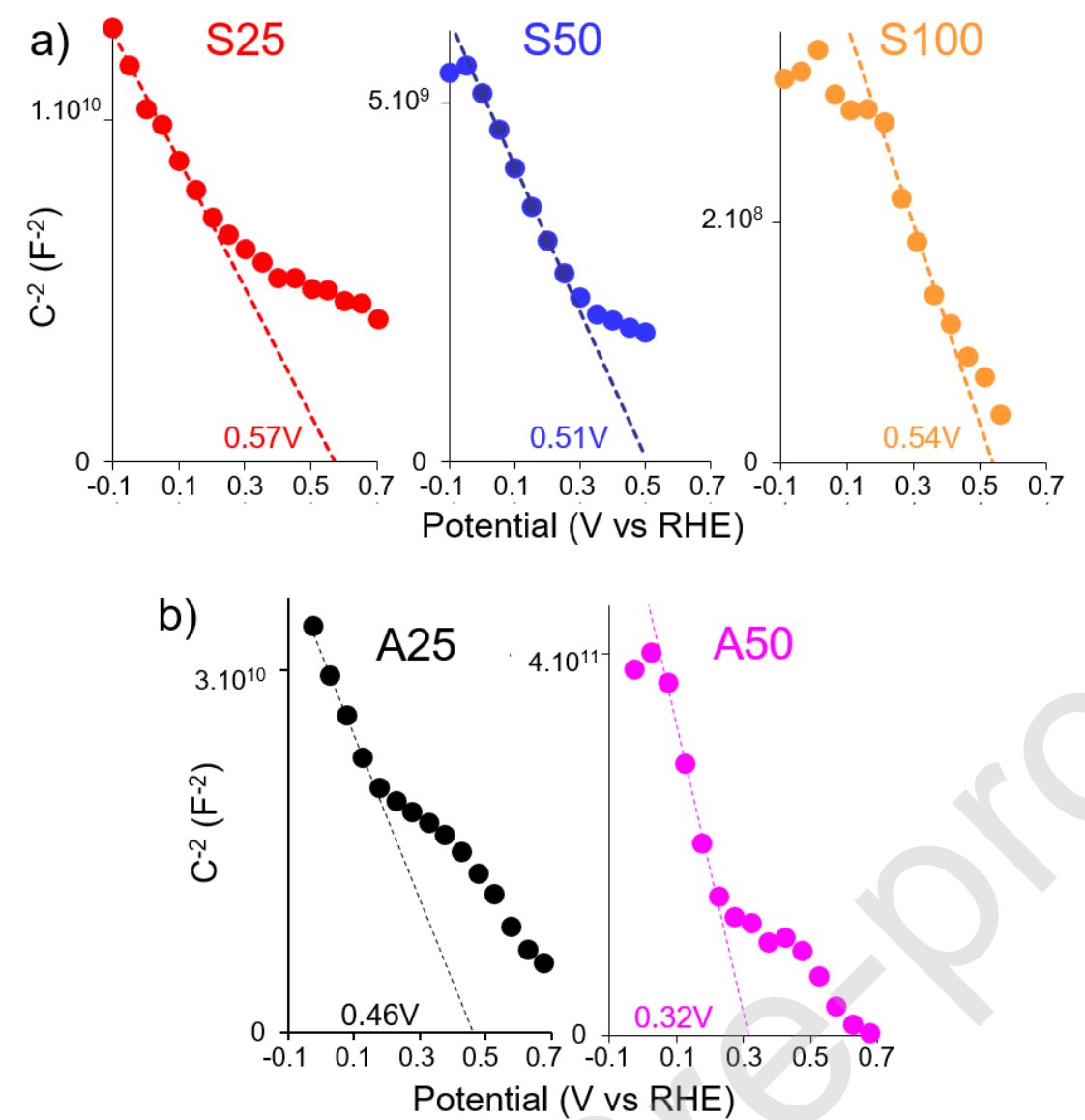

Figure 3. Mott-Schottky plots for (a) stoichiometric and (b) off stoichiometric CZTSSe samples

The relationship between $1 / \mathrm{C}_{\mathrm{sc}}{ }^{2}$ and $\mathrm{V}$ is linear in depletion region and the negative slope observed for all samples confirms the expected p-type behavior (see Figure 3a) [19].

For potentials higher than $0.5 \mathrm{~V}$, a second slope is observed on all plots due to a surface reactivity into the electrolyte. This reaction being very pronounced for the compound S00, its flat-band potential could not be determined by EIS.

The flat-band potentials versus $\mathrm{SCE}\left(\mathrm{V}_{\mathrm{SCE}}=0.241 \mathrm{~V}\right.$ vs NHE$)$ were extrapolated to $\mathrm{C}_{\mathrm{SC}^{-2}}=$ 0 and then calculated versus RHE (reversible hydrogen electrode) on an absolute vacuum scale using formulae (1) et (2): 
$\mathrm{V}_{\mathrm{fb}}$ versus $\mathrm{RHE}=\mathrm{V}_{\mathrm{fb}}$ versus $\mathrm{SCE}+0.059 \mathrm{pH}+\mathrm{V}_{\mathrm{SCE}}$

$E_{f b}$ versus $A V S=-4.5 e V-V_{f b}$ versus $R H E$

As summed up in Table 3, the S/Se ratio has no influence on the Fermi level position since the value of $E_{F}$ is the same for all compounds.

Table 3: Characteristic of energy diagrams of studied powdered CZTSSe samples

\begin{tabular}{lllllll}
\hline sample & S00 & S25 & A25 & S50 & A50 & S100 \\
\hline $\mathbf{E g}(\mathbf{e V})$ & 1.05 & 1.16 & 1.16 & 1.28 & 1.28 & 1.48 \\
$\mathbf{V}_{\mathbf{f b}} \mathbf{R H E}(\mathbf{V})$ & - & 0.57 & 0.47 & 0.51 & 0.32 & 0.54 \\
$\mathbf{E F}_{\mathbf{F}}(\mathbf{e V})$ & - & -5.1 & -5.0 & -5.0 & -4.9 & -5.0 \\
$\mathbf{V B M}(\mathbf{e V})$ & -5.5 & -5.2 & -5.6 & -5.3 & -5.4 & -5.3 \\
$\mathbf{C B M}(\mathbf{e V})$ & -4.4 & -4.0 & -4.4 & -4 & -4.1 & -3.8 \\
\hline
\end{tabular}

By combining Eg, VBM and $\mathrm{E}_{\mathrm{F}}$ values, an energy diagram sketched in Figure 4 can be proposed for all compounds. Because CdS is commonly used as buffer material in CZTS solar cells, its energy diagram is also shown for comparison. For S00, in order to minimize surface reactivity, the VBM was deduced from a shorter cyclic voltammetry analysis, in which one of the anodic peaks observed could be co-related to the electron transfer mediated through valence band edge. The VBM value thus obtained $(-5.5 \mathrm{eV})$, matched well with the one reported previously in the literature. 


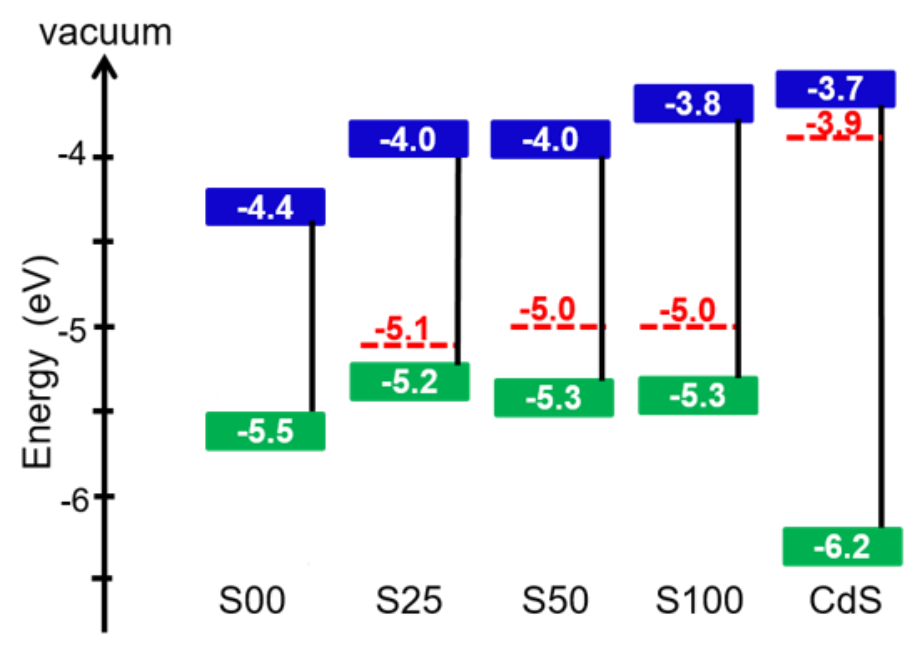

Figure 4: Schematic representation of the band structures of CZTSSe compounds on an absolute energy scale (VB in green, $\mathrm{CB}$ in blue, $\mathrm{E}_{\mathrm{F}}$ in red)

As for Fermi level, the nature of the anion has also slight influence on the VBM. However, the CBM increases with the sulfur content (from -4.4 to $-3.9 \mathrm{eV}$ ). These results are in very good agreement with those described in the literature for thin films and nanocrystals [21-22, 24]. Moreover, since the conduction band of all stoichiometric compounds is lower than that of CdS, a "spike-like" offset has to be privileged over "cliff-like" one.

Conversely, the influence of the copper deficiency on the band edge parameters is notable. Comparing the energy diagram of the stoichiometric compounds S25 and S50 with those of their corresponding Cu-poor compounds A25 and A50 (see Figure 5), a band energy shift towards a deeper level is experimentally observed, as predicted by density functional theory (DFT) calculations [25-27]. This is concomitant with a slight but significant decrease of the flat band potential, around 110-190 mV for A25 and A50, respectively (see Figure 3b). Consequently, a notable difference of the Fermi level positioning with respect of VBM is observed between the $\mathrm{Cu}$-poor compounds and the stoichiometric ones. 


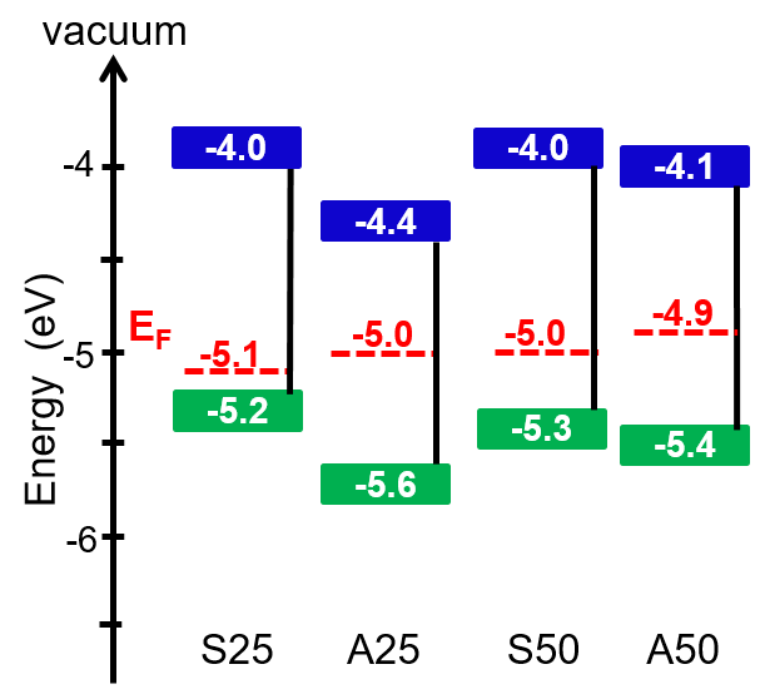

Figure 5: Schematic representation of the band structures of the stoichiometric compounds S25 and S50 compared to their corresponding Cu-poor compounds A25 and A50.

Thus, the Fermi level of Cu-poor compounds move away from the VBM ( 0.6 eV), positioning itself close to the middle of the gap as expected for the formation of midgap states due to A-type defects (i.e. $\left.2 \mathrm{Cu}_{\mathrm{Cu}} \rightarrow \mathrm{Zn}_{\mathrm{Cu}}+\mathrm{V}_{\mathrm{Cu}}\right)[25]$. The acceptor densities $\left(\mathrm{N}_{\mathrm{A}}\right)$ of stoichiometric $\left(\sim 10^{20}\right.$ and $10^{19} \mathrm{~cm}^{-3}$ for $\mathrm{S} 25$ and $\mathrm{S} 50$, respectively) and $\mathrm{Cu}$-poor $\left(\sim 10^{22} \mathrm{~cm}^{-3}\right.$ for A25 and A50) compounds were therefore estimated from the slope of Mott-Schottky plots. Although these values are overestimated because of the underestimated of the interfacial surface area between the porous semiconductor electrodes and the electrolyte, it appears indeed that $\mathrm{N}_{\mathrm{A}}$ of the $\mathrm{Cu}$-poor compounds are two or three orders of magnitude lower than those of stoichiometric ones. These features could induce a significant change in the electrical conductivity of these compounds. 


\section{Conclusion}

The synthesis of CZTSSe compounds with a well-determined chemical composition made it possible to study precisely the influence of the anionic composition as well as that of the non-stoichiometry of copper, on the position of the bands edges and the Fermi level.

The influence of the S/Se ratio had already been described in the literature while that of the $\mathrm{Cu}$ deficiency had been studied mainly by DFT calculations. Our results allowed to experimentally corroborate these theoretical studies.

While the anionic composition mainly influences the optical gap and the CBM, the $\mathrm{Cu}$ deficiency enhances optical absorption without modification of the optical gap. Moreover, the positioning of the Fermi level with respect to the VBM is notably modified and this latter shifts towards a deeper energy level. This feature could induce a significant change in the electrical conductivity of these compounds These results confirm the key importance of controlling precisely the chemical composition of CZTSSe compounds concerning to their use as absorbers in photovoltaic devices.

\section{Declaration of interests}

The authors declare that they have no known competing financial interests or personal relationships that could have appeared to influence the work reported in this paper.

Author statement

All authors have contributed in multiple roles.

\section{Acknowledgements}

The authors thank the Region Pays de la Loire and the Synchrotron SOLEIL for the cofinancing of P.B. Ph-D. thesis. 


\section{References}

[1] Sustainable Energy \& Fuels (2019), 3, (9), 2246-2259

[2] T. Gokmen, O. Gunawan, T.K. Todorov, D.B. Mitzi, Appl. Phys. Lett. (2013), 103, 103506. doi:10.1063/1.4820250.

[3] A. Lafond, L. Choubrac, C. Guillot-Deudon, P. Deniard, S. Jobic, Z. Anorg. Allg. Chem. (2012), 638, 2571.

[4] Lafond, A.; Choubrac, L.; Guillot-Deudon, C.; Deniard, P.; Jobic, S., Z. Anorg. Allg. Chem. (2012), 638, 2571-2577.

[5] S. Giraldo, Z. Jehl, M. Placidi, V. Izquierdo-Roca, A. Pérez-Rodríguez, E. Saucedo, Adv. Mater. (2019), 31, 1806692

[6] P. Bais, M.T. Caldes, M. Paris, C. Guillot-Deudon, P. Fertey, B. Domengès, A. Lafond, Inorg. Chem. (2017), 56, 11779-11786. doi:10.1021/acs.inorgchem.7b01791.

[7] M. Paris, L. Choubrac, A. Lafond, C. Guillot-Deudon, S. Jobic, Inorg. Chem. (2014), 53, 8646-8653

[8] S. Chen, A. Walsh, X.-G. Gong, S.-H. Wei, Adv. Mater. (2013), 25, 1522-1539.

doi:10.1002/adma.201203146.

[9] A. Crovetto, O.Hansen,, Solar Energy Materials and Solar Cells (2017), 169, 177-194

[10] Y. Udaka, S. Takaki, K. Isowaki, T. Nagai, K. Min Kim, S. Kim, H. Tampo, H. Shibata, K. Matsubara, S. Niki, N. Sakai, T. Kato, H. Sugimoto, N. Terada, Phys. Status Solidi C (2017), 14, No. 6, 1600178. doi: 10.1002/pssc.201600178

[11] I.D. Olekseyuk, I.V. Dudchak, L.V. Piskach, J. Alloys Compd. 368 (2004) 135-143. doi:10.1016/j.jallcom.2003.08.084.

[12] I.V. Dudchak, L.V. Piskach, J. Alloys Compd. (2003) 6.

[13] P. Schöppe, G. Gurieva, S. Giraldo, G. Martınez-Criado, C. Ronning, E. Saucedo, S. Schorr, C. S. Schnohr, APPLIED PHYSICS LETTERS (2017), 110, 043901

[14] M. Paris, G. Larramona, P. Bais, S. Bourdais, A. Lafond, C. Choné, C. Guillot-Deudon, B. Delatouche, C. Moisan, G. Dennler, J. Phys. Chem. C. (2015), 119, 26849-26857. doi:10.1021/acs.jpcc.5b08938.

[15] A. Polizzotti, I.L. Repins, R. Noufi, S.-H. Wei, D.B. Mitzi, Energy Environ. Sci. (2013), 6, 3171. doi:10.1039/c3ee41781f.

[16] K. Pal, P. Singh, A. Bhaduri, K. B. Thapa, Solar Energy Materials and Solar Cells (2019), 196, 138-156

[17] Neal Fairley, CasaXPS Software Ltd, n.d.

[18] H. Yang, L.A. Jauregui, G. Zhang, Y.P. Chen, Y. Wu, Nano Lett. (2012), 12, 540-545. doi:10.1021/nl201718z.

[19] Adrian W. Bott, Current separations, (1998) 87-91.

[20] G. Rey, A. Redinger, J. Sendler, T.P. Weiss, M. Thevenin, M. Guennou, B. El Adib, S. Siebentritt, Appl. Phys. Lett. (2014), 105, 112106. doi:10.1063/1.4896315.

[21] S. Huang, W. Luo, Z. Zou, J. Phys. D: Appl. Phys. (2013), 46235108 (6pp)

[22] Y.A. Jadhav,P.R. Thakur,S.K. Haram, Solar, Energy Materials \&Solar Cells (2016), 155, 273-279.

[23] A. Khare, B. Himmetoglu, M. Cococcioni, E. S. Aydil, Journal of Applied Physics (2012), 111, 123704, doi: 10.1063/1.4728232

[24] S. Ji, T. Shi, X. Qiu, J. Zhang, G. Xu, C. Chen, Z. Jiang, C. Ye, Scientific Reports (2013), 3, 2733, doi: 10.1038 
[25] A. Polizzotti, I. L. Repins, R. Noufi, S-H. Weib, D. B. Mitzic, Energy Environ. Sci. (2013), 6, 3171, doi: 10.1039/c3ee41781f

[26] S. Bourdais, C. Choné, B. Delatouche, A. Jacob, G. Larramona, C. Moisan, A. Lafond, F. Donatini, G. Rey, S. Siebentritt, A. Walsh, G. Dennler, Adv. Energy Mater. (2016), 6, 1502276, doi: 10.1002/aenm.201502276

[27] J. Li, D. Wang, X. Li, Y. Zeng, Y. Zhang, Adv. Sci. (2018), 5, 1700744, doi:

10.1002/advs.201700744 